\title{
AN ORIENTED VERSION OF THE 1-2-3 CONJECTURE
}

\author{
Olivier Baudon, Julien Bensmail
}

AND

Éric SOPEnA

Univ. Bordeaux, LaBRI, UMR 5800, F-33400 Talence, France

CNRS, LaBRI, UMR 5800, F-33400 Talence, France

e-mail: olivier.baudon@labri.fr

julien.bensmail@labri.fr

eric.sopena@labri.fr

\begin{abstract}
The well-known 1-2-3 Conjecture addressed by Karoński, Łuczak and Thomason asks whether the edges of every undirected graph $G$ with no isolated edge can be assigned weights from $\{1,2,3\}$ so that the sum of incident weights at each vertex yields a proper vertex-colouring of $G$. In this work, we consider a similar problem for oriented graphs. We show that the arcs of every oriented graph $\vec{G}$ can be assigned weights from $\{1,2,3\}$ so that every two adjacent vertices of $\vec{G}$ receive distinct sums of outgoing weights. This result is tight in the sense that some oriented graphs do not admit such an assignment using the weights from $\{1,2\}$ only. We finally prove that deciding whether two weights are sufficient for a given oriented graph is an NP-complete problem. These results also hold for product or list versions of this problem.
\end{abstract}

Keywords: oriented graph, neighbour-sum-distinguishing arc-weighting, complexity, 1-2-3 Conjecture.

2010 Mathematics Subject Classification: 68R10, 05C15.

\section{REFERENCES}

[1] B. Seamone, The 1-2-3 Conjecture and related problems: a survey, Technical Report, available at http://arxiv.org/abs/1211.5122 (2012).

[2] W. Imrich and S. Klavžar, Product Graphs: Structure and Recognition (WileyInterscience, New York, 2000). 
[3] J.W. Moon, Topics on Tournaments (Holt, Rinehart and Winston, 1968).

[4] J. Skowronek-Kaziów, 1,2 conjecture-the multiplicative version, Inform. Process. Lett. 107 (2008) 93-95. doi:10.1016/j.ipl.2008.01.006

[5] M.R. Garey and D.S. Johnson, Computers and Intractability: A Guide to the Theory of NP-Completeness (W.H. Freeman, 1979).

[6] M. Kalkowski and M. Karoński and F. Pfender, Vertex-coloring edge-weightings: Towards the 1-2-3 conjecture, J. Combin. Theory (B) 100 (2010) 347-349. doi:10.1016/j.jctb.2009.06.002

[7] T. Bartnicki, J. Grytczuk and S. Niwczyk, Weight choosability of graphs, J. Graph Theory 60 (2009) 242-256. doi:10.1002/jgt.20354

[8] M. Borowiecki, J. Grytczuk and M. Pilśniak, Coloring chip configurations on graphs and digraphs, Inform. Process. Lett. 112 (2012) 1-4. doi:10.1016/j.ipl.2011.09.011

[9] M. Khatirinejad, R. Naserasr, M. Newman, B. Seamone and B. Stevens, Digraphs are 2-weight choosable, Electron. J. Combin. 18 (2011) \#1.

[10] M. Karoński, T. Łuczak and A. Thomason, Edge weights and vertex colours, J. Combin. Theory (B) 91 (2004) 151-157. doi:10.1016/j.jctb.2003.12.001

[11] O. Baudon, J. Bensmail, J. Przybyło and M. Woźniak, On decomposing regular graphs into locally irregular subgraphs, Preprint MD 065 (2012), available at http://www.ii.uj.edu.pl/preMD/index.php.

[12] L. Addario-Berry, R.E.L. Aldred, K. Dalal and B.A. Reed, Vertex colouring edge partitions, J. Combin. Theory (B) 94 (2005) 237-244. doi:10.1016/j.jctb.2005.01.001

Received 8 October 2013

Revised 17 March 2014

Accepted 29 April 2014 